\title{
Analytical Study of Fiber Reinforced Post Tensioned Slab
}

\author{
Muthulingam.M \\ M.E.Structural Engineering \\ SRM Valliammai Engineering College \\ Chennai, India
}

\author{
Suganya Devi \\ Assitant Professor, Dept of Civil Engineering \\ SRM Valliammai Engineering College \\ Chennai, India
}

\begin{abstract}
Post-Tensioning allows almost any shape of structure to be constructed, while reducing environmental impacts, construction time, materials and costs. Since the PT technology has advanced significantly - particularly in the field of performance, quality assurance and durability as well as corrosion protection. Parameters varied were, amount of reinforcement, and location of reinforcement. Readings from strain gages on the rebar were used to investigate the impact of PT slab on the service stresses. Crack width measurements were made at regular intervals and compared to strain readings. In SFRC PT slabs, service stress limits were reached at larger demands than in RC slabs. When service stress limits were reached in SFRC PT slabs, crack widths were much smaller than common crack width limits, suggesting design for crack widths may be an appropriate method for addressing serviceability in SFRC PT slabs. This paper presents the Post-tensioning of slab using the steel Fibers.
\end{abstract}

\section{Keywords : Steel fibers, Post-Tensioning, ANSYS.}

\section{INTRODUCTION}

Post tensioning is a technique for reinforcing concrete. Post-tensioning tendons, which are pre-stressing steel cables inside plastic ducts or sleeves, are positioned in the forms before the concrete is placed. Afterwards, once the concrete has gained strength but before the service loads are applied, the cables are pulled tight, or tensioned, and anchored against the outer edges of the concrete.

There are two types of Post-Tensioning, they are Bonded post-tensioning and Unbonded post-tensioning.

Bonded post-tensioned concrete is the descriptive term for a method of applying compression after pouring concrete and during the curing process (in situ). The concrete is cast around a plastic, steel or aluminium curved duct, to follow the area where otherwise tension would occur in the concrete element.

A set of tendons are fished through the duct and the concrete is poured. Once the concrete has hardened, the tendons are tensioned by hydraulic jacks that react (push) against the concrete member itself. When the tendons have stretched sufficiently, according to the design specifications (Hooke's law), they are wedged in position and maintain tension after the jacks are removed, transferring pressure to the concrete. The duct is then grouted to protect the tendons from corrosion. This method is commonly used to create monolithic slabs for house construction in locations where expansive soils (sometimes called adobe clay) create problems for the typical perimeter foundation.

All stresses from seasonal expansion and contraction of the underlying soil are taken into the entire tensioned slab, which supports the building without significant flexure. Post-tensioning is also used in the construction of various bridges, both after concrete is cured after support by false work and by the assembly of prefabricated sections, as in the segmental bridge. Unbonded posttensioned concrete differs from bonded post-tensioning by providing each individual cable permanent freedom of movement relative to the concrete.

\section{MATERIALS AND METHODS}

\section{A. Raw materials and mix proportion}

Ordinary Portland cement of 43 grades is used for the investigation. Locally available coarse aggregates are taken and sieved to the required quantity of volume to the maximum nominal size of $10 \mathrm{~mm}$. Care is taken to arrive the size of coarse aggregate ranging from $4.75 \mathrm{~mm}$ to the maximum nominal size of $10 \mathrm{~mm}$.

Preliminary tests are carried as per IS standard on the material used for concrete like specific gravity for cement. For fine and coarse aggregates tests such as sieve analysis, specific gravity, impact value, crushing value are conducted as per standards. M35 grade of concrete is used for the casting of column specimen and the mix proportion is designed as per the standards according to the values which is arrived in the preliminary test. The mix proportion for M35 grade of concrete is 1:1.6:2.907.

\section{B. Post-Tensioning materials}

In this paper, the materials used for Post-tensioned are steel Fiber and Tendons. steel fiber types are available as reinforcement. Round steel fiber the commonly used type are produced by cutting round wire in to short length. The typical diameter lies in the range of 0.25 to $0.75 \mathrm{~mm}$. Steel fibers having a rectangular $\mathrm{c} / \mathrm{s}$ are produced by silting the sheets about $0.25 \mathrm{~mm}$ thick. Fiber made from mild steel drawn wire. performance fiber reinforced composite is developing quickly to a modern structural material with a high potential. Fiber-reinforced concrete (FRC) is concrete containing fibrous material which increases its structural integrity.

Both end hooked steel fibers are used for made the HPFRC and the properties of steel fibers are listed below.

Table- I Properties of steel fiber

\begin{tabular}{|c|c|}
\hline PROPERTIES & VALUES \\
\hline Diameter & 0.75 \\
\hline Length of fiber & $60 \mathrm{~mm}$ \\
\hline Aspect ratio & 80 \\
\hline Tensile strength & $1050 \mathrm{MPa}$ \\
\hline Modulus of elasticity & $200 \mathrm{GPa}$ \\
\hline Specific gravity & 7.8 \\
\hline
\end{tabular}




\section{Casting of specimen}

The c/s dimension of the PT slab is $1000 \mathrm{~mm} x$ $1000 \mathrm{~m}$ and the Thickness is $100 \mathrm{~mm}$ and the slab is designed as a short column. The ingredients of concrete such as cement, fine aggregate, coarse aggregate of maximum nominal size of $10 \mathrm{~mm}$ are weighed accurately using the platform weighing machine. The ingredients are mixed manually and adequate amount of water is added to the constituents of concrete. The mixing is done till to get uniform mix of concrete is obtained. After the casting of column specimen, it was get cured for 28 days in the curing tank.

\section{Post-Tensioning of PT slab}

After 28 days of curing, the Pt slab is post tensioned while anchorages and wedge plates are provided at end of the slab. Then tendons are inserted into duct and tightened with the help of anchors

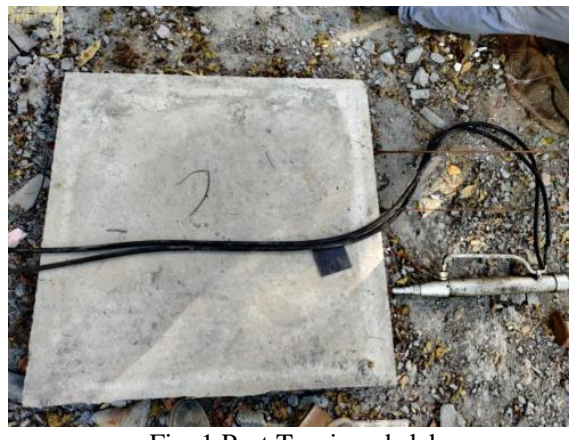

Fig. 1 Post Tensioned slab

Hydraulic jack is fixed to the tendons, after that jack is checked for the stability, After fixing the tendons are stressed by applying load to it. The breaking load of tendons is $6 \mathrm{KN}$, so a safe load of $2 \mathrm{KN}$ is given to the tendons . By stressing the tendons it is elongated upto $30 \mathrm{~mm}$ in length. The elongated area is marked with the marker and left for $24 \mathrm{hrs}$ to avoid slippage of the tendon . After $24 \mathrm{hrs}$ the elongated tendons has been cut down and leaving small length of wire around $20 \mathrm{~mm}$.

\section{A. General}

\section{SOFTWARE ANALYSIS}

The ANSYS Workbench environment is an intuitive up-front finite element analysis tool that is used in conjunction with CAD systems and/or Design Moeller. ANSYS Workbench is a software environment for performing structural, thermal, and electromagnetic analyses.

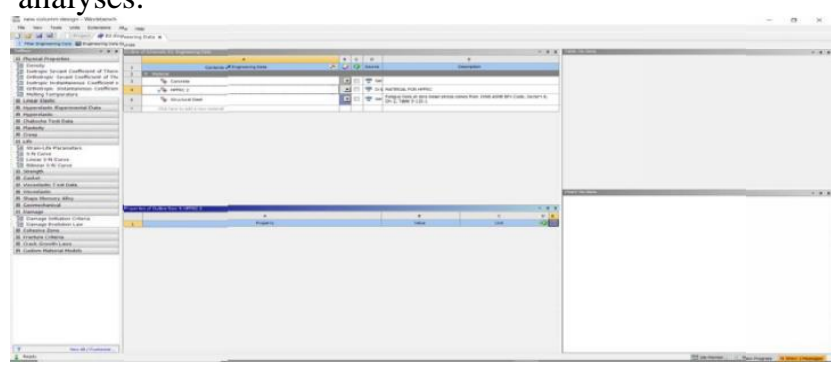

Fig.2 Assigning the materials in engineering data

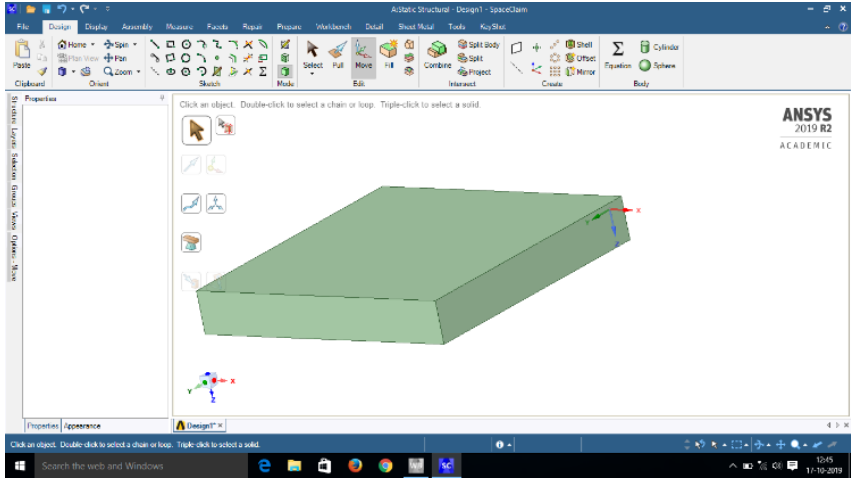

Fig.3 Geometry of column in design modeler

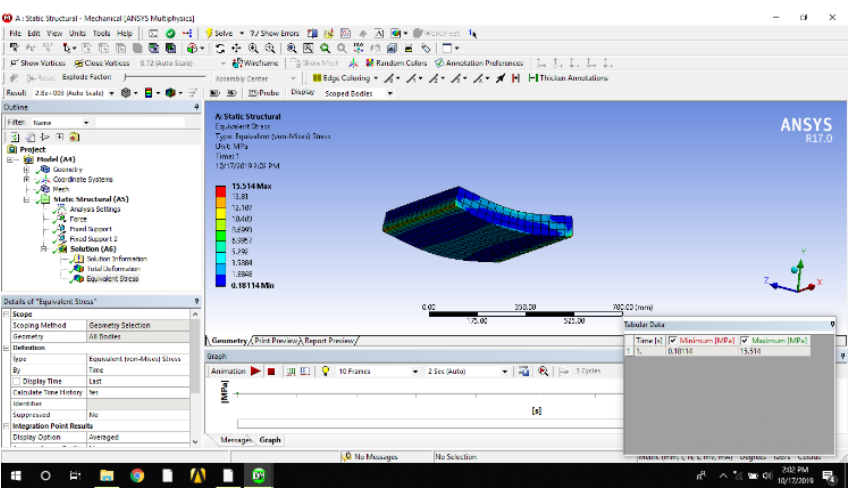

Fig.4 Equivalent Stress

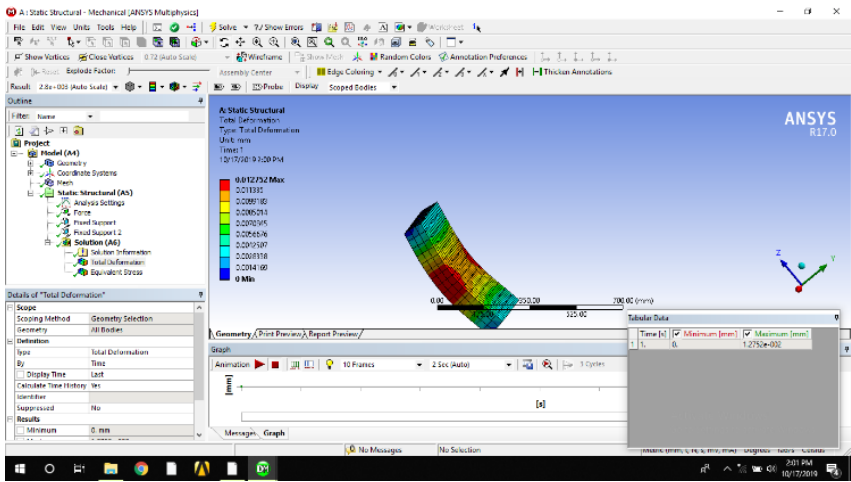

Fig. 5 Total deformation

IV. CONCLUSION

Literature review has been done properly and most the data about Post tensioning of the column and the uses of high performance fiber reinforced concrete in the Post-Tension technique has been collected using the literature. PT slab size and properties of steel fibers and HPFRC have been fixed and the calculation of the maximum load has also been done. Using those results analytical design has been done in ANSYS Software, and the results have been obtained in the terms of deflection and maximum stresses. A series of reinforced concrete PT slab specimens for seismic 
A series of Steel Fiber reinforced concrete PostTensioned slab specimens with applications of Steel fiber-reinforced composites (SFRC) analysed using ANSYS software. The increasing amount of steel fibers in PT slabs results in the increase of both, the punching shear resistance and the energy absorption capacity in comparison to slabs without fibers. The effect of steel fibers on punching shear resistance of higher-strength concrete slabs has shown to be lower than that of lower-strength concrete slabs. Furthermore, the contribution of the steel fibre was captured by the finite element model due to the implemented tensile behaviour of the SFRC, containing the residual tensile strength. The parameter study of the tensile properties of SFRC showed that the finite element model was relatively sensitive to the tensile model, especially when the strain energy of the system was increased results. In addition to efficiency and reduced cost during construction, the structure has sufficient ductility in ultimate limit state.

\section{REFERENCES}

[1] Duarte M. V. Faira et al (2011) -Strengthening of flat Slabs with Post-tensioning using anchorages by bonding. Journal name-Engineering structures, vol no-33pg2025-2043.

[2] Gianluca Ranzi et al (2013) -An experimental study on the ultimate behaviour of simply-supported post-tensioned composite slabs. Journal name- Journal of construction steel research,vol no-89,pg293-306.

[3] Gianluca Ranzi et al (2017)-Ultimate Behaviour and design of post-tensioned composite slabs. Journal name-Engineering structures,vol no-150,pg711-718.

[4] Iosif Torok et al (2019) -Post-Tensioned Flat slabs with unbonded tendons for public building. Journal nameEngineering structures vol no-32, pg102-109.

[5] Joshua A et al (2017) -Service performance of steel fiber reinforced concrete (SFRC) slabs. Journal name-Engineering structures,vol no-168, pg58-68.

[6] Luca Facconi et al (2016) Experimental study Steel fiber reinforced self-compacting concrete thin slabs. Journal nameEngineering structures,vol no-122, pg226-237.

[7] Ahmed Met al (2016) Punching shear behavior of reinforced concrete slabs using steel fibers in the mix. Journal nameEngineering structures, vol no-14,pg272-281.

[8] Hamzeh Hajiloo et al (2019) GFRP reinforced concrete slabs in fire: Finite element modelling. Journal name-Engineering structures,vol no-183,pg1109-1120.

[9] Nhat-Duc Hoang et al (2019) -Estimating punching shear capacity of steel fibre reinforced concrete slabs using sequential piecewise multiple linear regression and artificial neural network. Journal name-Engineering structures vol no137,pg58-70.
[10] GianlucaRanziet al (2017) Ultimate behaviour and design of post-tensioned composite slabs. Journal name-Engineering structures ,vol no-150,pg711-718.

[11] Thibault Clémentet al (2014) -Influence of prestressing on the punching strength of post-tensioned slabs. Journal nameEngineering structures vol no-72,pg56-69.

[12] Chung-CheChouet al (2008) Seismic design and behavior of post-tensioned steel connections including effects of a composite slab. Journal name-Engineering structures vol no-30, pg3014-3023.

[13] LongNguyen-Minh al (2012) Punching shear resistance of post-tensioned steel fiber reinforced concrete flat plates. Journal name-Engineering structures, vol no-45,pg324-337.

[14] Hamidreza Salehianal (2017) -Prediction of the load carrying capacity of elevated steel fibre reinforced concrete slabs. Journal name-Engineering structures vol no-170 pg169-191

[15] Stine Maria et al (2019) Impact response of hybrid FRP-steel reinforced concrete slabs. Journal name-Engineering structures, vol no- $19, \mathrm{pg} 436-448$. 